\title{
Mathematics Problem Solving Ability: An Analysis Based on IDEAL Problem Solving Viewed from Learning Style
}

\author{
Gita Pratiwi ${ }^{1, *}$ Imam Sujadi $^{2}$ Isnandar Slamet $^{3}$ \\ ${ }^{1}$ Postgraduate of Mathematics Education, Faculty of Teacher Training and Education, Universitas Sebelas \\ Maret, Surakarta, Indonesia \\ ${ }^{2}$ Departemen of Mathematics Education, Universitas Sebelas Maret, Surakarta, Indonesia \\ ${ }^{3}$ Departemen of Statistict, Universitas Sebelas Maret, Surakarta, Indonesia \\ *Corresponding Author. Email: gitapratiwi@student.uns.ac.id
}

\begin{abstract}
IDEAL problem solving is model that able to improve skills in the problem-solving process and improve the ability to think. This study aims to describe the problem-solving ability student of Junior High School $8^{\text {th }}$ grades on IDEAL problem solving viewed from the learning style. This type of research is qualitative research with a case study research design. Subjects were selected by purposive sampling method. Hence, 3 students were selected and became subjects on their respective learning styles, namely visual learning style (S1), auditory learning style (S2), and kinesthetics learning style (S3). The data collection techniques of this research were tests and interview. The validity of the data using triangulation method. Data analysis includes data reduction, data presentation and conclusions. The results showed that the subject S1 could fulfill the IDEAL problem-solving steps of the first, third and fourth stages. Subject S2 are only able to fulfill the first stage. And subject S3 could fulfill the IDEAL problem solving all of steps except second stages.
\end{abstract}

Keywords: IDEAL problem-solving, Problem-solving ability, Learning style.

\section{INTRODUCTION}

Problem solving is one of a series of processes carried out by students in dealing with situations defined in questions, and challenging to solve even though strategies cannot be immediately determined to answer the questions at hand. Some expert opinions that support the importance of problem solving for students, among others, state that (1) All education goals are to train students in problem solving [1]. (2) An important component in mathematics education is problem solving wich is the only place to be found at school [2]. (3) the Nasional Council of Mathematics Teachers in the reform document stated that the fator of change in mathematics education in schools was problem solving, that is why problem solving became the center of mathematics in school [3].

From the explanation of the importance of problem solving, it is necessary to develop students' problemsolving ability. Students' mathematic problem-solving ability is a necessary ability in learning and mathematics itself. By training students in mathematics problem solving, it can help students get used in problem solving life now and in the future.

However, textbooks are still the main guide in learning mathematics, the reality in this field is not as expected, it is not uncommon for mathematics teachers to still be materialized in their teaching habits by using learning steps such as: presenting learning materials, providing examples of questions and asking questions. Students work on practice questions contained in the textbooks they use in teaching and then discuss them with students. Learning like this is certainly less able to develop students mathematical problem-solving abilities. If students are given different task, they will have dificuly solving them, because student are only able to the examples given by the teacher. Learning mathematics problem solving can be meaningful as a processes chain in an effort to resolve problems [4]. There are various problemsolving models known so far. Either them is problem solving from Gick consisting of 3 stages, namely, constructing the problem, finding a solution and using/implementing the solution [5]. The famous 
problem solving model is Polya which consists of 4 stages, namely understanding the problem, planning a solution, solving the problem according to the plan, and re-checking all the steps that have been done [6].

The other problem-solving model that researchers are interested in researching is IDEAL problem solving. This model was introduced by Bransford and Stein as a problem solving model that is able to improve the ability to think and improve skills in the problem solving process [7]. IDEAL stands for IIdentify, D-Define, E-Explore, A-Act, L-Look. The steps in learning IDEAL problem solving according to Bransford are (1) Identify the problem, (2) Define the goal, (3) Explore strategies, (4) Act on the strategies, and (5) Look back. In problem solving the second step is goal setting where there is no problem solving from Polya in this step, this is what makes the difference between IDEAL and problem solving according to other experts.

The process of problem solving's between individuals must be different, this is due to their habits, understanding of concepts, and learning styles. One thing that distinguishes the way of problem solving is the learning style. When someone knows their learning style, it is very useful in the learning process because it can help someone in learning faster and easier. Identify each learning style provides an effective advantage in problem solving. That is why learning style are important in an individual's life [8]. If each individual can manage under what conditions, where, when and how his learning style is, then learning will be more effective and efficient so that learning achievement is higher. Because learning styles are believed to improve a person's achievement or learning outcomes.

The learning styles of students are basically different. The diversity of students in the way they learn is the impact of this. The difference in the learning styles of these students is also the teacher must be able to determine how to deliver learning material so that all students can understand and get more and more understandable learning material so that students are enabled to increase concentration [9]. Learning styles be composed of visual learning styles, auditory learning styles and kinesthetics learning styles [10]. Therefore, it is notable to conduct research on problem solving abilities based on IDEAL problem-solving steps. The purpose of this research is to describe students' mathematics problem solving ability based on IDEAL problem solving in terms of their respective learning styles.

\section{RESERCH METHOD}

This research is a type of qualitative method with a case study research design. This research is to provide an overview of the natural condition of the object with the researcher as the key instrument [11]. This research was conducted at SMP Negeri 33 Bandar Lampung. The time of data collection for this research was carried out in July 2021. The subjects of this study were 3 students of $8^{\text {th }}$ grades taken based on the visual learning style, auditory learning style and kinesthetics learning style, then interviewed based on the test results. This subject is taken by purposive sampling or taking the subject based on certain considerations [12].

Data collection techniques were implemented by providing learning style questionnaires, problem solving ability tests and interviews. The number of questions consists of linier equation is 1 task with 3 questions. First, a learning style questionnaire was given to 28 students in a class, then 1 student was taken each with a visual learning style, an auditory learning style and a kinesthetic learning style. Furthermore, 3 students who were selected as research subjects were given a problem-solving ability test. The interview used is a semi-structured interview to find out more about the ability to solve mathematical problems.

The activities of data analysis are carried out by reducing the data needed for research. That is by selecting the main data so that the research still focuses on what is being studied. After that the data is presented in the form of a description. After the data is reduced and presented, the next step is to conclude according to the purpose of the problem or answer the problem formulation [13]. Data testing or data validation is done by triangulation. Triangulation method and triangulation of data were used in the research that was checked by the data form the task result with the data of interviews. The stage of data analysis in this research insert: (1) giving the task to the student; (2) analyzing of the task with interviews subject; and (3) conclusion.

\section{RESULTS DISCUSSION}

Based on the tests conducted in $8^{\text {th }}$ grades, the test results are grouped into categories visual learning style, auditory learning style, and kinesthetic learning style. The answer sheets of 3 subjects will be analyzed further according to the IDEAL problem-solving step and the three subjects will be interviewed. Interviews were conducted to confirm answers in the problemsolving process as well as other possible findings that will be obtained during the interview.

IDEAL problem solving is a model introduced by Bransford and Stein as a model of problem solving that is able to rectify thinking skills and look up thinking skills and improve skills in the process of problem solving. IDEAL stand up for I-Identify, D-Define, EExplore, A-Act, L-Look. The steps in learning IDEAL problem solving according to Bransford are (1) 
Identify the problem, (2) Define the goal, (3) Explore strategies, (4) Act on the strategies, and (5) Look back.

The first step of IDEAL problem solving is [14] trying to identify (Identify) the problem and make it as an occasion (occasions) carry out about creativity. One of the reasons for deliberately looking for trouble and turning it into an opportunity is that people often don't realize that events are not "the reality of life".

The second step of the IDEAL is developing an understanding of the problems that have been identified and trying to define (Define) goals. Setting goals is dissimilar from identify problems. For example, a group of people may identify a problem and agree that the problem can be an opportunity but they sometimes disagree with the desired goal. A problem that exists depends on how they set goals, and this has a significant impact on the type of answer to be attempted. contrary in goal setting can be a very strong cause of a person's ability to understand problems, think and solve problems. Different goals lead people to explore different strategies for solving problems.

The third step of IDEAL is to explore (Explore) feasible strategies and assess the possibility of these strategies in approval with the objectives that have been set. Some of the strategies in problem solving are very general and can be used in almost any problem. But some strategies are very specific and only used in certain cases.

The fourth step of IDEAL is to expect results and act (Act). The moment a strategy is chosen, it look forward possible outcomes and then acts on the strategy chosen. Anticipating the results that will come in handy from things will be regretted at a later date.

The last stage of IDEAL is to see (Look) the evident consequences of the strategies used and study from the experience gained. Looking back needs to be done because to see whether the result obtained are in accordance with the goals or not.

Based on answer analysis from 3 subjects on the steps for solving problems based on IDEAL problem solving, the analysis and discussion were obtained as follows:

\subsection{Visual Learning Style Subject}

\subsubsection{Identify the Problem}

Subject S1 (visual learning style) based on the results of the answers to the problem-solving ability test questions can identify problems well. S1 can write down all the information needed to complete and write it down as completely as possible. In writing information, the subject S1 writes completely and clearly according to the question. The questions used can be seen in Figure 1. Student results can be seen in Figure 2.

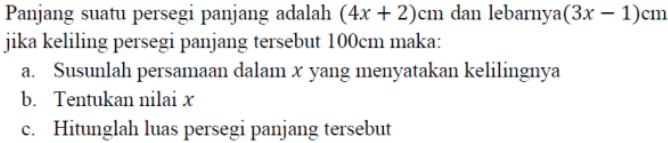

Figure 1 Question

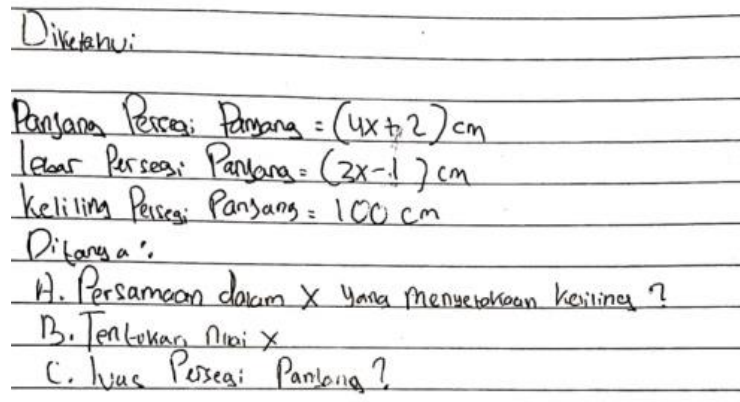

Figure 2 Identify the problems S.1.

Furthermore, interviews were conducted to confirm the results of student work:

Q : "Can you understand that the task given? Explain."

$\mathrm{S} 1$ : "What I knew is to calculate the perimeter and find the area."

Q : "Did you write down what you knew about the question?"

$\mathrm{S} 1$ : "I wrote the length of the rectangle is $4 x+$ $2 \mathrm{~cm}$, the width of the rectangle is $3 x-1$ $\mathrm{cm}$ and the perimeter of the rectangle is $100 \mathrm{~cm} . "$

Q : "Are the questions from $a, b$, and $c$ not something you knew or a problem that you should know about?"

$\mathrm{S} 1$ : "The questions is not known but asked."

In the results of the interview with the $\mathrm{S} 1$, he did not answer very clearly what was understood from the test but he understood what was known and what information was known from the question and wrote it completely. However, S1 was used to written what is asked as something that is not known as information, the $\mathrm{S} 1$ considers the known and the questions is a different stage of problem solving.

\subsubsection{Define the Goal}

Based on the results of interviews with the subjects $\mathrm{S} 1$ obtained as follows:

Q : "Based on that question, do you know the goals you want to achieve?" 
S1 : "I don't know."

Q : "Did you write down the goals you want to achieve on the answer sheet?"

$\mathrm{S} 1$ : "no"

Based on the results of the interview, the $\mathrm{S} 1 \mathrm{did}$ not know what the goal to be achieved was, even though he understood what was the questions and what problems were in the task. When asked if he knew what his goal was, he said he didn't know. The S1 were not accustomed to written down the goals to be achieved from mathematical problems solving because they assumed that the goals were the same as known.

\subsubsection{Explore Strategies}

Based on the results of the problem-solving ability test questions given to the three research subjects, it is known that the subject $\mathrm{S} 1$ is able to write strategies or formulas to be used to answer the objectives to be achieved completely and accurately. S1 can write strategies to determine the perimeter and strategies to find the area of a rectangle. It can be seen in Figure 3.

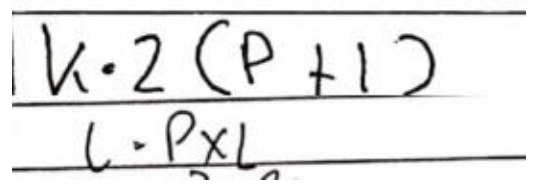

Figure 3 Explore strategy S.1.

Based on the results of interviews with the S1 obtained as follows:

Q : "Do you know a strategy or a method to solve the problem?"

$\mathrm{S} 1$ : "How to find the perimeter is $2(p+l)$. While finding the area is $p \times l$."

Based on the results of interviews, subject S1 have strategies to solve math problems on all questions. When the researcher asked how to solve the problem, the subject $\mathrm{S} 1$ answered that the method was to determine the perimeter with the formula $2(p+l)$, then if you have obtained the equation of the perimeter, you can get a value of $x$, and if you have got a value of $x$, then you can find the area of the rectangle.

\subsubsection{Act On the Strategies}

Based on the results of interviews with the $\mathrm{S} 1$, it was found that:

Q : "Do you know how to act on the strategy or method you have chosen? Explain."

$\mathrm{S} 1$ : "To find the perimeter by replacing the known values of $p$ and $l$ (substitution) a arithmetic operation will be able to produce the perimeter in the form. After that, from the perimeter we can determine the value by moving the side (equivalent). Furthermore, after getting the $x$ value, it can be entered (substitution) into the equation of length and width, then the value of the area of the rectangle can be searched."

Subject S1 can carry out all the strategies he used. In carrying out the problem strategy in question a, he using the perimeter formula produces the correct answer, then after getting the perimeter in the equation, will get a value of $x$, then the value of the area of the rectangle is obtained.

\subsubsection{Look Back}

The following are the results of interviews with the subject $\mathrm{S} 1$ :

Q : "What do you get from the strategy you have used before?"

$\mathrm{S} 1$ : "I get the value of the area of the rectangle is $600 \mathrm{~cm}^{2}$."

Q : "What the conclusions you obtained in accordance with the objectives to be achieved?"

S1 : "Yes already."

Q : "Did you write down the conclusions you got?"

S1 : "No."

Based on the results of the answers, the $\mathrm{S} 1$ did not wrote a conclusion, although the S1 did not write a conclusion, the S1 knew the results obtained after implementing the strategy used and knew that the strategy, he had executed produced a rectangular area value. Based on the interview, it is known that the $S 1$ said that the answers obtained were in accordance with the objectives to be achieved.

For problem-solving ability of IDEAL problem solving, the subject $\mathrm{S} 1$ can fulfill the first step in IDEAL problem solving, where students can identify the problem and mention the information needed. It is a pity that the subject $\mathrm{S} 1$ could not fulfill the second step in IDEAL problem solving because S1 ca not written the goal he knew on the answer sheet. the third step in IDEAL problem solving, S1 can fulfill for exploring strategies or ways to mathematical problem solving on the task of problem-solving ability. And then $\mathrm{S} 1$ can fulfill the fourth step in IDEAL problem solving, namely Act on the strategies. So, the subject $\mathrm{S} 1$ cannot fulfill the last step in IDEAL problem solving. 


\subsection{Auditory Learning Style Subject}

\subsubsection{Identify the Problem}

Subject S2 (auditory learning style) can identify problems well. S2 can write all the information needed to solve the problem and write it in the form of symbols. In writing information, the subject $\mathrm{S} 2$ writes briefly and completely by using symbols. Student results can be seen in Figure 4.

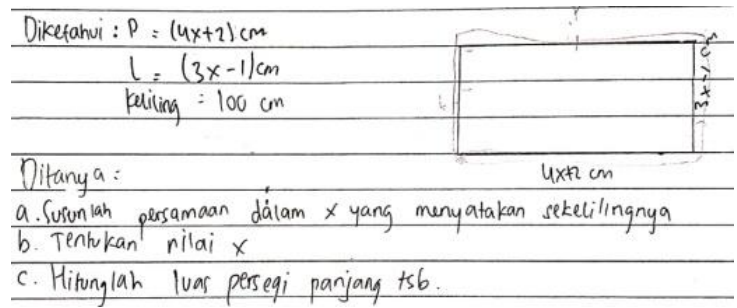

Figure 4 Identify the problems S.2.

Furthermore, interviews were conducted to confirm the results of student work

$$
\begin{aligned}
& \mathrm{Q}: \text { "Can you understand that the task given? } \\
& \text { Explain." } \\
& \mathrm{S} 2: \text { "No, I only wrote what I knew." } \\
& \mathrm{Q}: \text { "The length is } 4 x+2 \mathrm{~cm} \text {, the width is } \\
& \text { 3x-1 cm, and the perimeter is } 100 \mathrm{~cm} . " \\
& \mathrm{~S} 2: \text { "Yes already." } \\
& \mathrm{Q}: \text { "Are the questions from a, b, and c not } \\
& \text { something you knew or a problem that you } \\
& \text { should know about?" } \\
& \mathrm{S} 2: \text { "That's what was asked." }
\end{aligned}
$$

The subject S2 was asked whether she understood the test given, $\mathrm{S} 2$ answered that she did not understand the test given but she knew what information from the test and wrote it in the form of symbols. Similar to the $\mathrm{S} 1$, the subject $\mathrm{S} 2$ assumes that what is known and the questions is a different stage or step in problem solving.

\subsubsection{Define the Goal}

Based on the results of interviews with the subjects S2 obtained as follows:

Q : "Based on that question, do you know the goals you want to achieve?"

$\mathrm{S} 2$ : "The goal is to find the area of the rectangle."

Q : "Did you wrote down the goals you want to achieve on the answer sheet?"

$\mathrm{S} 2$ : "No"

The subject S2 when asked if she knew the goal she wanted to achieve from the problem, she replied that her goal was to find the value of the area of a rectangle. And when asked if she wrote down the goals, she knew on the answer sheet she said no, because according to her, she had written down the goals in the known steps. The S2 were not accustomed to written down the goals to be achieved from mathematical problems solving because they assumed that the goals were the same as known.

\subsubsection{Explore Strategies}

Subject S2 only wrote a strategy to find the area of the rectangle correctly. It can be seen in Figure 5.

$$
\text { Rumus }=P \times l
$$

Figure 5 Explore strategy S.2.

Based on the results of interviews with the S2 obtained as follows:

$$
\begin{aligned}
& \mathrm{Q}: \text { "Do you know a strategy or a method to } \\
& \text { solve the problem?" } \\
& \mathrm{S} 2 \text { : "I forgot to find the perimeter, but for } \\
& \text { finding the area of the rectangle is } p \times l . "
\end{aligned}
$$

The subject S2 when asked about the strategy to solve the problem she answered that she did not know how to find the perimeter. Even when the researcher asked S2 to remember what the formula for the perimeter of a rectangle was, she answers $2 p \times 2 l$. It indicates that the $\mathrm{S} 2$ does not remember how to find the perimeter of a rectangle. However, when the researcher asked if she knew how to find the area of a rectangle, the $\mathrm{S} 2$ answered that the formula for the area of a rectangle is $p \times l$.

\subsubsection{Act On the Strategies}

For S2, she cannot carry out the strategies that have been prepared, because the previous strategies were incomplete.

Based on the results of interviews with the S1, it was found that:
Q : "Do you know how to act on the strategy or method you have chosen? Explain."

$\mathrm{S} 2$ : "I don't know."

The subject S2 cannot fulfill the fourth step in IDEAL problem solving, namely Act on the strategies.

\subsubsection{Look Back}

The following are the results of interviews with the subject $\mathrm{S} 2$ :

Q : "What do you get from the strategy you have used before?"

$\mathrm{S} 2$ : "I don't know." 
Q : "What the conclusions you obtained in accordance with the objectives to be achieved?"

$\mathrm{S} 2$ : "I don't know."

Q : "Did you wrote down the conclusions you got?"

$\mathrm{S} 2$ : "No."

Because the S2 cannot carry out the chosen strategy, the S2 does not know what is obtained and concluded from the question.

For problem-solving ability of IDEAL problem solving, the subject S2 can fulfill the first step in IDEAL problem solving, where students can identify the problem and mention the information needed. It is a pity that the subject $\mathrm{S} 2$ could not fulfill the second step in IDEAL problem solving, because she not written the goal on the answer sheet. The third stage of IDEAL problem solving S2 were unable to fulfill, because she cannot complete the strategies that should be used. And then S2 cannot fulfill the fourth step in IDEAL problem solving, because the strategies are not complete. So, the subject S2 cannot fulfill the last step in IDEAL problem solving.

\subsection{Kinesthetics Learning Style Subject}

\subsubsection{Identify the Problem}

Subject S3 (kinesthetic learning style) can identify problems well. S3 can write down all the information needed to complete and write it down as completely as possible. In writing down information, S3 writes completely and clearly in consent with the questions. Student results can be seen in Figure 6 .

$\begin{array}{r}\text { diketahui: panjang: } 4 x+2 \\ \hline \text { lepar: } 3 x-1 \\ \hline \text { keliling: } 100\end{array}$

ditanya a. Persamoan dalam $x$ yang meryaraken koling?
6. tenruken' nilai $x$
c. tulis persegi panjang.

Figure 6 Identify the problems S.3.

Furthermore, interviews were make to confirm the results of student work:

Q : "Can you understand that the task given? Explain."

S3 : "Yes, I know, find the area based on the known length, width and perimeter."

Q : "Did you write down what you knew about the question?"

$\mathrm{S} 3$ : "Length is $4 \mathrm{x}+2 \mathrm{~cm}$, width is $3 \mathrm{x}-1 \mathrm{~cm}$, and perimeter is $100 \mathrm{~cm}$."
Q : "Are the questions from $a, b$, and $c$ not something you knew or a problem that you should know about?"

S3 : "Isn't that what was asked?"

For the subject S3, she understood the problem that from the 3 questions given the final task was to find the value of the area of a rectangle. And can write briefly whatever is known. Not different from subjects $\mathrm{S} 1$ and $\mathrm{S} 2$, the subject $\mathrm{S} 3$ also assume that what is known and the questions is in the form of different stages of problem solving.

\subsubsection{Define the Goal}

Based on the results of interviews with the subjects S3 obtained as follows:

Q : "Based on that question, do you know the goals you want to achieve?"

S3 : "First determine the perimeter, then find the value of $x$ and calculate the area of the rectangle."

Q : "Did you wrote down the goals you want to achieve on the answer sheet?"

$\mathrm{S} 3$ : "No"

Likewise with the subject S3 she knew for sure that the goal he wants to achieve is to determine the perimeter, then find the value of $\mathrm{x}$ and calculate the area of the rectangle. But when asked why she didn't write down the goal of solving the problem, she replied that she had already written down the goal in the asked. The S3 were not accustomed to written down the goals to be achieved from mathematical problems solving because they assumed that the goals were the same as known.

\subsubsection{Explore Strategies}

Then the S3 subject was able to write a strategy to write the strategy used to answer the goals to be achieved completely and correctly, he wrote the formula for the perimeter of a square and also the area of a rectangle. It can be seen in Figure 7.

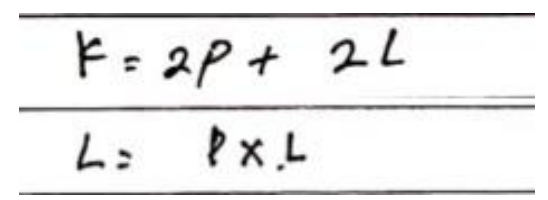

Figure 7 Explore strategy S.3.

Based on the results of interviews with the S3 obtained as follows:

Q : "Do you know a strategy or a method to solve the problem?" 
$\mathrm{S} 3$ : "Find the perimeter of the rectangle is $2 p+2 l$. If you want find the area of the rectangle is $p \times l$."

Subject S3 have strategies to mathematical problem solving on all questions. Subject S3 explained that the way to solve the problem is to determine the perimeter in the $x$ equation, after that it can determine the value of $x$, then from that value you can get the length and width values of the rectangle, then with the length and width values you can find the area of the rectangle.

\subsubsection{Act On the Strategies}

The S3 have implemented the strategies used previously and produced the correct answers. Based on the results of interviews with the S1, it was found that:

Q : "Do you know how to act on the strategy or method you have chosen? Explain."

S3 : "Yes, ma'am, first find the perimeter and multiply it, then add up what's $x$ in it and add up what's $x$ not in the sum to find the perimeter of the rectangle Then, from the equation of perimeter, we move the segment to get the value of $x$. Once we can we can find the area."

The subjects S3 can fulfill the fourth step in IDEAL problem solving, namely Act on the strategies.

\subsubsection{Look Back}

The following are the results of interviews with the subject S3:

Q : "What do you get from the strategy you have used before?"

S3 : "To get the perimeter, get the value of $x$, and get the value of the area of the rectangle."

Q : "What the conclusions you obtained in accordance with the objectives to be achieved?"

S3 : "Already."

Q : "Did you wrote down the conclusions you got?"

S3 : "yes, I wrote."

The S3, she can know the results obtained after implementing the chosen strategy, and knew that the conclusions obtained are in accordance with the objectives to be achieved, and wrote the conclusions on the answer sheet.

For problem-solving ability of IDEAL problem solving, the subject S3 can fulfill the first step in
IDEAL problem solving, where students can identify the problem and mention the information needed. Like otherwise that the subject S3 could not fulfill the second step in IDEAL problem solving, because she not written the goal on the answer sheet. The S3 can fulfill the third step in IDEAL problem solving, namely exploring strategies or ways to mathematical problem solving on the task of problem-solving ability. For the fourth step in IDEAL problem solving, namely Act on the strategies, the subjects S3 can fulfill. For the last the subject S3 can fulfill the last step in IDEAL problem solving.

Based on the overall analysis, it can be concluded that students with visual, auditory and kinesthetic learning styles have different problem-solving abilities. However, the three research subjects have in common that the three research subjects can determine the goals to be achieved from mathematical problem solving, but are not accustomed to writing them down on the answer sheet.

\section{CONCLUSION}

Based on the analysis of the data above, the ability to solve problems based on IDEAL problem solving in terms of learning styles can be concluded as follows: Subject S1 with visual learning style, in the first stage, namely identify the problem, is able to identify problems and write down what is known as well as the information needed to mathematical problem solving completely and correctly, so he can fulfill in this stage. In the second stage, namely define the goal, the subject knows the goal to be achieved to mathematical problem solving but cannot write it down on the answer sheet, he unfulfilled this stage. In the third stage, namely explore strategies, the subject knows the strategy that will be used to realize the goal of mathematical problem solving, so he can fulfill on this stage. In the fourth stage, namely act on the strategies, the subject can carry out all the strategies used properly, so he can fulfill this stage. In the fifth stage, namely look back, the subject can see the consequences after implementing the strategy, know the answers obtained are in the goal with the objectives to be achieved but he not write the conclusions, so he unfulfilled this stage.

Subject S2 with auditory learning style, in the first stage, namely identify the problem, the subject is able to identify problems and write down what is known as well as the information needed to mathematical problem solving completely and correctly, so she can fulfill this stage. In the second stage, namely define the goal, the subject knows the goal to be achieved to mathematical problem solving but cannot write it down on the answer sheet, she unfulfilled the stage. In the third stage, namely explore strategies, the 
subject does not know what strategy should be used to solve the problem. As a result, the subject cannot fulfill the next stage until the end.

Subject S3 with a kinesthetic learning style, in the first stage, namely identify the problem, the subject is able to identify problems and write down what is known as well as the information needed to mathematical problem solving completely and correctly, she can fulfill this stage. In the second stage, namely define the goal, the subject knows the goal to be achieved to mathematical problem solving but cannot write it down on the answer sheet, she unfulfilled this stage. In the third stage, namely explore strategies, the subject knows the strategy that will be used to realize the goal of mathematical problem solving, she can fulfill this stage. In the fourth stage, namely act on the strategies, the subject can carry out all the strategies used properly, so she can fulfill this stage. In the fifth stage, namely look back, the subject can see the consequences after implementing the strategy, knowing the answers obtained in the goal and written the conclusions on the answer shed.

\section{ACKNOWLEDGMENTS}

The author thanks a lot the researchers to embroiled in the ensuing references for look up the quality of this article and as well to the Head of SMP Negeri 33 Bandar Lampung for the chance and facilities to do the research

The author would like to express our gratitude to the Head of SMP Negeri 33 Bandar Lampung. We thank also the mathematics teacher in this school who helped us to selecting the subjects for this research

\section{REFERENCES}

[1] M. Adogdu, M. F. Ayaz, The importance of problem solving in mathematic curriculum, Ejournal of New World Sciences Academy Natural and Applied sciences, Elasig-Turkiey, 2008, pp. 538-545. DOI: https://doi.org/10.12739/10.12739

[2] M. Taplin, Mathematics through problem solving, Institute of SathyaSai Education, Hong Kong, 2006.

[3] National Council of teachers of mathematics, principles and standards for school mathematics, VA: Reston.

[4] W. Blum, M. Niss, Applied mathematical problem solving, modeling, applications, and links to other subjects: state, trends and issues in mathematics instruction, Educational Studies in Mathematics, New York, Springer, 1991, pp. 37-
68. DOI: https://doi.org/10.1007/BF00302716

[5] M. L. Gick, Problem-solving strategies, Educational psychologist, Francis, 1986, pp. 99120.

DOI: https://doi.org/10.1080/00461520.1986.9653026

[6] G. Polya, how to solv it: a new aspect of mathematical method, Princeton University Press, Princeton, New Jersey, 2004.

[7] J. Bransford, B. S. Stein, The ideal problem solver: a guide for improving thinking, learning, and creativity (2nd ed), W.H. Freeman:New York, 1984.

[8] M. A. Bhat, The effect of learning style on problem solving ability among high school students, Internasional Journal Advance in Social and Humanities, Department of Education, Aligarh Muslim University, U. P., India, 2018.

[9] B. DePorter, M. Hernacki, Quantum learning: unleashing the genius in you, Dell publishing, 1992.

[10] A. Salido, D. Dasari, Student errors in solving probability problems viewed by learning style, Journal of Physics: Conference Series, 2019. DOI: $\quad$ https://doi.org/10.1088/17426596/1211/1/012067

[11] H. Wijaya, Metode penelitian pendidikan teologi,E-Modul, pp. 1-8, 2013.

[12] L. J. Moleong, Metodepenelitiankualitatif, RemadjaKarya, 1989.

[13] M. B. Miles, A. M. Huberman, Qualitative data analysis: a sourcebook of new methods, Sage Publications, USA, 1994.

[14] J. Bransford, Teaching thinking and problem solving, Research foundation, American Psychologist, 41(10), 1007-1089, 1986.DOI:https://doi.org/10.1037/0003066X.41.10.1078 